\title{
Disease Resistance in Plants
}

$\mathrm{V}$ OL. 3, No. 6, of the Proceedings of the Indian Academy of Sciences is devoted entirely to the papers submitted for the symposium at Coimbatore in October 1935 on "Disease Resistance in Plants". Interest in the contributions lies in methods of stimulating disease resistance. These are adopted as a result of investigations along the lines of inheritance of resistance, structural modification associated with resistance and physiological conditions associated with the plants' response to the disease. Thus in the case of sugar-cane, frequently attacked by mosaic, N. L. Dutt, Syed Abbas Hussainy and M. K. Krishnaswami ; C. S. Krishnaswami, and others, have found it possible to breed resistant plants and that those with Saccharum spontaneum parentage are more resistant than others.

Other workers, investigating the wilt disease of cotton (due to attacks of Fusarium species), have found that environmental conditions are important factors in relation to susceptibility, and in particular soil management can control the disease. A striking example of this is furnished by the work of B. B. Mundkur, who shows conclusively that in the case of Fusarium vasinfectum the American variety could not attack American cottons on Indian soils, and will not attack Indian cottons in any circumstances, whilst Indian cottons are less susceptible to the Indian variety of Fusarium on American soils. It is interesting to note that American soil in affected districts is light sandy and acidic, whilst affected Indian soils are heavy clayey and alkaline. Soil conditions (mainly physical) have also been found by J. Madhusudan Rao and Yeshwant D. Wad to be responsible for development of leaf roll and red leaf in American cottons.

With reference to anatomical developments in relation to disease, B. P. Pal shows that in certain varieties of gram (Cicer Arietinum L.) which are affected by the cutworm, those which are relatively immune have large stem diameters and extensive development of woody tissues, while severely attacked varieties show a smaller stem diameter and poorly developed secondary wood.

In most cases work has been carried out under field conditions and in connexion with various growers, so that some very interesting statistics are possible in view of the quantity of material available.

\section{Progress in Building Research}

\begin{abstract}
A PERUSAL of the report of the Building Research Board for 1935 recently issued by the Department of Scientific and Industrial Research (H.M. Stationery Office. $3 s$. 6d.) shows how elementary is our scientific knowledge of building technique. In his introductory survey of the recent work of the Board, Dr. R. E. Stradling, the director of research, suggests that a wrong emphasis has been given by concentrating on the engineering side, strength and stability of structure being studied to the neglect of other equally vital considerations associated with the "Efficiency of Buildings from the Standpoint of the User".

Recent developments have given special prominence to three of these problems, especially in connexion with slum clearance schemes. The increase of noises of all kinds and the influence of mechanical continuity, as adopted in modern construction, in causing a sound made at one point to be extended over a large area, have made the sound insulation problem serious and pressing. The results of earlier work on walls, partitions and floors, treated individu. ally, have focused attention on the interaction of the several elements of a building, and this is now being investigated with the full realization of treating the building as a whole. Trials are in progress on a frame building, on the principle that the construction should be such as to confine the noise to the room in which it is made; and this is arranged as a box, built into, but acoustically insulated from, a structural framework. It is appreciated that unforeseen troubles may arise in the full-scale developments, but "these must be overcome for the need is urgent".
\end{abstract}

From the same source comes the difficult problem of bug infestation, in which the survey work carried out has shown that virtually every urban authority is more or less troubled with this problem. Dr. Stradling urges that the building industry should endeavour to contribute to its solution by preventing the formation of cracks and by devising a form of construction which will, when the need arises, admit of disinfestation by the poisonous gases at present used, without danger to the occupants of surrounding houses.

It is claimed that considerable advance has been made towards placing the investigation of fire resistance on a scientific basis by the provision of a fire-testing station at Elstree, where full-size building elements are tested and graded in accordance with the new specification. Arrangements have been made for a programme of research covering not only the investigation of different forms of construction but also of tests of proprietary systems with the view of issuing appropriate certificates.

In the demolition of Waterloo Bridge, opportunity has been taken to investigate the condition of granite after exposure for 120 years. The outer halfinch was found to be seriously affected, but no reason appeared to suggest that decay would have become apparent in the near future had the structure been undisturbed. Laboratory examination of Portland stone from St. Paul's Cathedral also showed that, except for surface portions, the material was sound and, with regard to the use of old stones, the report states that, in the case of the more durable kinds, provided an appropriate thickness is removed, these should prove as good as new. 
Materials for cleaning buildings have been under review, and a number of proprietary preparations investigated. It is pointed out that it is inadvisable to use chemical methods, and that alkalis are equally as dangerous as acids. Examples of the deleterious effects of cleaning in stone walls, door jambs, etc., are quoted.

Work on the effect of firing conditions on the properties of bricks has shown that specimens fired to below $900^{\circ} \mathrm{C}$. offered only a moderate resistance to disruption by the crystallization of soluble salts whereas, with one exception, all the clays tested proved satisfactory in this respect when fired to $1,000^{\circ} \mathrm{C}$. The unsightly efflorescence on brickwork is caused by soluble magnesium compounds, particularly the sulphate, contained in the bricks, and the only certain method of its elimination is firing to a temperature of above $1,050^{\circ} \mathrm{C}$.

The report also contains particulars of tests made on the heating, cooling and lighting of buildings. The notable difference in the temperatures inside a wooden shed, before and after whitening it, is shown in the results of one inquiry, while the diminution of the lighting of a room due to a balcony or neighbouring building is the subject of another. Particulars of the work carried out in conjunction with other bodies and on behalf of manufacturers, indicate the value of the scientific services rendered by the Building Research Board both to the industry and to the interests of the public.

\section{The Machinery of the Queen Mary}

\begin{abstract}
7 HE ninth Thomas Lowe Gray lecture was delivered before the Institution of Mechanical Engineers on January 8 by Mr. John Austin, super. intendent engineer, Cunard White Star, Ltd., and took the form of a description of the main and auxiliary machinery of the Queen Mary.

Mr. Austin pointed out that since the advent of steam propulsion, the trend of development in the design of Atlantic liners has been towards larger and faster ships, and the several commercial and technical considerations which determined the size and speed of the new vessel were explained. Before a decision was taken as to the type of machinery to be installed, a committee of eminent engineers was invited to advise the directors, and they unanimously recommended high-pressure water-tube boilers with superheaters and air-preheaters and, for propulsion, single reduction geared turbines as being most suitable by reason of their reliability, simplicity, lightness, efficiency and freedom from noise and vibration. To meet emergencies and to maintain the fortnightly schedule, a large reserve of steaming capacity was provided and, in relation to the normal power required, it is of particular interest to the engineer to note how much design of hull and propellers has improved. From the table of figures given, the Lucania of 1893 had a gross tonnage of 12,952 , horse-power 27,650 and speed $21.9 \mathrm{knots}$. The Queen Mary has 6.2 times the tonnage, but only $5 \cdot 7$ times the horse-power, although her speed is $1 \cdot 2$ times that of the Lucania.
\end{abstract}

The arrangements to ensure economy and to obviate delays and damage are as complete as human ingenuity can make them. Salt-water detectors are fitted at every point where salt-water might leak into the feed-water system, and give audible and visible warning when the concentration reaches 2 grains per gallon. Automatic feed-water regulators ensure a steady water-level in the boilers. The adoption of the closed stokehold system of forced draught has obviated the need for massive air ducts, and maintains better ventilation and working conditions. Fach boiler has a complete system of steam soot blowers, and the arrangement by which boilers and propelling machinery have been divided into two quite independent systems-only practicable in a ship of such large size and power-ensures that, in the event of breakdown in one section, the whole propelling machinery is not put out of action.

The steering and mancuvring of a ship of this size necessitates a rudder of large area and, this being of streamline unbalanced type, powerful operating gear had to be installed. The torque is supplied by four hydraulic rams acting on tillers projecting from the rudder-stock. For safety, the essential parts were duplicated and the pumps are driven by three electric motors each of 250 h.p., the switchboard of which is operated by servo gear of the electro-hydraulic type controlled by hydraulic telemotors working in conjunction with the steering wheel on the bridge.

\section{Crystalline Structure of Cellulose}

$\mathrm{P}$ ROF. K. H. MEYER reviews in the February issue of the Berichte der deutschen chemischen Gesellschaft the evidence upon which the structure of the crystalline part of cellulose has been based, and suggests that certain alterations are needed in the accepted model which was constructed from $\mathrm{X}$-ray intensity measurements carried out by Andress in 1929 .

Fortunately, the existing calculations upon the dimensions of the micelles or crystallites remain for the most part undisturbed, since the latter are independent units and the cellubiose type of linkage is not challenged. But the grouping of the micelles needs reconsideration. Hitherto it has been assumed that they all run in the same direction.

There seems to be no valid proof that this is the case, and the fact that precipitated hydratcellulose possesses the same crystal lattice as that of the mercerized fibre makes it highly improbable that all the chains are similarly orientated. There is, in fact, no reason why an equal number of chains should not be formed in opposite directions by precipitation. 